\title{
Synergistic development of accounting, finance and government in the chaotic environment: Integrated reporting, money theory and financial crises diagnostic
}

\author{
Svitlana Kuznetsova \\ Department of International Finance and Banking, Alfred Nobel University, Dnipropetrovs'k, Ukraine
}

\section{Email address:}

kuznet@meta.ua, fc@duep.edu

\section{To cite this article:}

Svitlana Kuznetsova. Synergistic Development of Accounting, Finance and Government in the Chaotic Environment: Integrated Reporting, Money Theory and Financial Crises Diagnostic. Journal of Finance and Accounting. Special Issue: Synergy of Accounting, Finance and Management in Chaotic Environment. Vol. 2, No. 6-1, 2014, pp. 1-7. doi: 10.11648/j.jfa.s.2014020601.11

\begin{abstract}
The modern world global challenges were formed in chaotic environment. The fundamental principles of government synergistic development have been described to the financial crises diagnostic and forming the ways to increase. The synergistic development of modern finance is shown as development monetarism and new money theory. Theoretical and methodological synergistic components of the transformation accounting in area of integrated reporting improvement have been grounded. The matrix key component of the integrated reporting, which includes 9 elements and determines the structure of such statements has been formed. 7 basic criteria which evaluate the effectiveness of integrated reporting have been proposed.
\end{abstract}

Keywords: Synergy, Accounting, Finance, Chaotic Environment, Integrated Reporting, Money Theory, Financial Crises, IFRS

\section{Introduction}

The economic transformation, which takes place in the world, has become an important prerequisite for scientific research related to the development and introduction of innovative approaches to informational support the management software users. Openness, uncertainty, dynamism and self-organization of world and national economy and unpredictable climatic conditions require proper information management, the creation of which is subject of traditional approaches to reporting.

Among the global challenges of the modern world it should be noted the following aspects: social networks, brands, virtualization, future of retail, corporate social responsibility, the war for talent, global computerization, demographic changes, significant costs of information in declining economies, rising unemployment, new trends in unstable economy, significant amounts of information, global supply network, global imbalance, increased pressure.

Current global economic and financial crisis escalates. Latest IMF report gives the evidence of this phenomenon: Global financial conditions improved further in the fourth quarter of 2012. However, a broad set of indicators for global industrial production and trade suggests that global growth have not strengthened [1]. The current chaotic stock market, banking system instability indicates the feature of worsening the global economic and financial crisis. Current global trends in economy and society impose fundamentally new demands on monetary policy and the banking system as a whole. Financial crisis, which consequence has influenced the whole world, the vast majority showed unwillingness of financial institutions to function in unstable conditions of internal and external economic environment.

Moreover, there is an undeniable failure to anticipate and predict the financial crisis on the part of contemporary international and public institutions, and by the vast majority of scholars and experts. In this context, J. Stiglitz stresses [2] that after every crisis there is an explanation that contradicted the next crisis or at least, it shows that the previous explanation was inadequate.

Applications developed by Robert F. Engle [3, 4, 5], Model $\mathrm{ARCH}$ allowed to anticipate volatility in any financial market. Thus, we can predict how much risk is contained in financial market. However, assessing global financial stability and the risks Robert F. Engle noticed [4] that economic studies show that almost impossible to predict when stock markets would rise or fall. 
Therefore, if we want to avoid future crises, we need to think about how to anticipate the risks and how to improve incentives for people not to neglect these risks.

Conducted by J. Stiglitz analyzes the causes and consequences of financial crises have allowed the author to assert [2] that in all cases, there is a common component: financial sectors behaved very badly and failed to assess creditworthiness and manage risk as it is expected from them.

The banking system is a major player in the money market and, therefore, globalization and modern society integration, which contributed the fundamentally new requirements for monetary policy formation in the individual countries and international financial institutions, led to the need for improvement. As Sheng E. said [6] the growth banking system past, based on retail deposit products, systems whose activity was directed on funding credit needs, borrowers become a Difficult ground and Global ground chain supply under this risks destabilizing in form "effect CTU domino" that can be compared to those that took place in Japan spring last year.

Based on researches of Friedman [7], Stiglitz J [8], Akerlof G. [9], Engle R. [3, 4, 5], Sheng A. [6] and the own results of previous studies $[10,11,12]$ in analyzing the current changes in the global and domestic economy; allocate existing relationships between financial crises, monetary policy, fiscal policy, the banking sector and monetary values (in particular, monetary aggregates and the monetary base).

Structural adjustment, which takes place in global economy caused by the transition from "industrial economy" to "knowledge economy", have characterized the dominance of information resource.

The evolution of economic relations is characterized by changes in information priorities of such a relationship. They are depending on the current operating conditions, status and specific needs of the user preference to certain types of information. This method of providing accounting information is constant - in the form of financial statements. According to the opinion of historians, beginning reporting is about the fourth millennium BC, when ancient civilizations of the Near East began to create highly organized state and establish economic activities [13].

A critical analysis of scientific and practical sources adequacy $[12,13,14,15,16,17,18]$ of modern conceptions of reporting requirements of management information indicates that significant problems of development and practical application users need urgent attention. Brukynh G., considering the use of accounting in the context of intellectual capital, said that the formation of accounting system needs to be reviewed so that it show the companies' need of the third millennium [14].

Thus, the current global challenges of our time require clarification and improvement of the theoretical and methodological foundations reporting for their adaptation to modern requirements management in the context of providing users with quality information through the synergy of such records and the creation of integrated reporting.

Informational support of financial markets should enable users to respond quickly to changes in the external and internal environment of economic actors (through incorporation of the impact of accidents on the society and economy). Overall, the current financial system must be able to create and provide information including not only existing, but also likely information needs of users.

This makes it necessary to use the innovative approaches to informational support and the need for comprehensive consideration of various levels and forms of relationships between the elements of the accounting, financial system and government, the evolution of which enhances their integrity and efficiency, the possibility of multiple in an unstable economic environment functioning based on statistical and dynamical laws and laws that have a decisive character to the overall evolution of the world economic system.

\section{Synergistic Development of Government: Financial Crises Diagnostic and Ways of Increasing}

Special attention should be also focused on contemporary change in the balance of economic power. We can be totally agree with the opinion of Stiglitz J. [8], which is considering the danger in 2012, he said that even before the crisis took place two centuries correction historical anomaly during which the fate of Asia in world GDP has declined from about $50 \%$ to $10 \%$. Modern trends to overall growth in the Asian sector were contributed, among other inefficiencies of European monetary policy, which essentially prevents further growth of European economy.

In order to take into account the existing Eurozone problems that directly affect the effectiveness of monetary policy as the sector and other related countries, including Ukraine. Among these problems, Stiglitz J. rightly singled out: the problem of tax competition, labor mobility (and, consequently, migration) and financial discipline. The mentioned issues should be considered in relationships and interaction (Fig. 1).

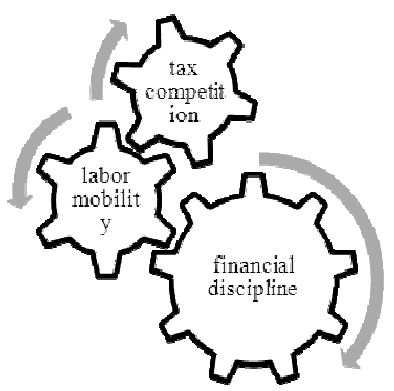

Figure 1. Recent developments in the Eurozone

Therefore, tax competition in the Eurozone leads, in particular, to the growth of labor migration. In its turn, the current ability of citizens to choose the country for work and residence, promotes opportunities to avoid so-called "debt burden". Thus, in the future will be distortion between economic indicators due to labor mobility. Definitions of things, in turn, causes the strengthening of financial discipline 
by reducing revenues for state budgets to countries with economic problems

Typically, for modern financial policies of European states is to control the budget deficit as an effective tool out of the financial crisis. Therefore, the next step is to evaluate the research strength of the relationship between the total monetary base state deficit (and surplus) budget and financial crisis. Therefore, it is vital to determine whether the budget deficit contributes financial imbalance. The analysis shows that there is no direct correlation between these parameters (Fig. 2).

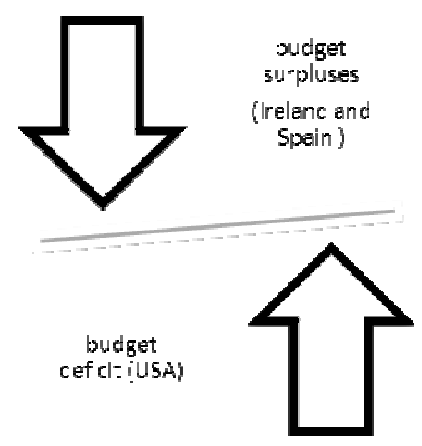

Figure 2. The financial crisis and the budget deficit

As Stiglitz J. rightly emphasized [8], before the crisis, Ireland and Spain had budget surpluses, while the United States - the budget deficit. So, financial discipline and fiscal policies are not effective tools to overcome and prevent crises.

\section{Synergistic Development of Finance: Monetarism in Development and New Money Theory}

Friedman noted the interesting fact that [7] the budget deficit does not stimulate the effect on the economy. Therefore, for short periods are most effective is monetary. However, in the long-term fiscal policy has a significant.

The outlined situation shows the lack of a clear theory which would provide explanations of financial crises, including, though, the consideration of the relationship of monetary values and distinguishing economic variables in modern chaotically structured economy, and consequently to predict the consequences of change.

As Friedman M. rightly stated [19], that it is necessary to have a very simple theory, which allows us to understand the essence of the phenomenon. Now theory will not be successful, if it is too complicated and is difficult. Therefore, what makes a good theory - a simplification, it identifies the driving forces and excludes others.

This shows the relevance of monetarism in the context of its use as a base concept of functioning money markets and the development of monetary policy in today's chaotic instability and general structuring of the world economy. Traditional concept and monetarism does not allow to fully response to the causes and consequences of financial crises and their possible prediction of the future. Meanwhile, M. Friedman paid attention [19] that if there is a stable demand function, it does not show that we can talk about it will not change and never, that it was not affect.

The most thorough definition of monetarism gave $M$. Friedman, "Monetarism is an objective set of assertions about the relationship between monetary values and other economic variables" [19]. Moreover, he stressed, and M. Friedman [19], stated that the economic system is so effective, when it can adapt to the dynamic changes.

Fully sharing the opinion of M. Friedman, who note that the current development of monetarism believe the selection of economic variables that have a relationship with money values in modern chaotically structured economy.

The current state of the global financial system Analysis reveals that the failure to overcome financial crises by modernizing influence the preventive measures, including change in financial policy and the use of financial instruments.

It is an indisputable constant decrease in the value of exchange at the time, because no currency is not bound by its own is value as a commodity. The inabilities of modern equivalents of money, such as gold, oil, gas, appear adequate measure of value. In fact, its resources are such that they are exhausted.

The development of electronic money causes their gradual devaluation and scattered and "dispersion" lack of values component. Therefore, we can observe the growth disparities between money as measure of value, which in the modern theory of money is not tied its own value and tends to decrease and the development of the economic system, which is based on demand, the desire to increase. The presence of the aforementioned contradictions and is a major cause of the current financial crisis, which will eventually be strengthened (Fig. 3).

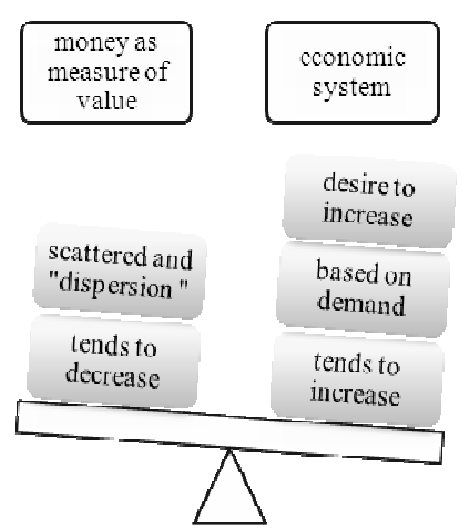

Figure 3. The growth disparities between money as measure of value and the modern development of the economic system

Thus, the direction of monetarism is to review economic variables that have a relationship with money values in modern chaotically structured economy. Determinants impact the cash value in today's chaotic economy is structured:

1. information asymmetries, reduction of which has profound importance due to the transition to a knowledge economy and society informational support; 
2. changing global economic balance (including redistribution of economic power in favor of the Asian region);

3. Eurozone problems (tax competition, labor mobility, fiscal discipline);

4. volatility of financial markets;

5. financial risks.

Prospects for further research are to develop effective mechanisms for financial risk management primarily for the banking sector, which is based to use the concept of maximization.

\section{Synergistic Development of Accounting: Integrated Reporting}

Synergy is to improve the reporting of such statements in the context of a comprehensive information support to its users because of the connection and integration of its individual components - reports in a single complex.

Based ensure synergy integrated reporting should be put application synergistic approach that allows you to find effective ways to control unstable system (in particular, a set of management reports). This approach is focused on knowledge of the laws of self-organization of complex objects in terms of chaotic spontaneous structuring. General theoretical basis for synergistic development of accounting in randomly structured economy was previously based [10].

With regard to the preparation of integrated reporting synergy causes increased efficiency of information management systems and society in general. It must come from the information needs of users of such information and take into account the peculiarities of society.

When using a synergistic approach, reporting should be considered as an open complex, determined by external and internal environment management entity within which it exists: self-organization; communication with the outside world; nonlinearity is the possibility of change.

Thus, synergy applied to integrated reporting, provides a comprehensive consideration for the need for different levels and forms of relations between the components of financial statements and management systems, the evolution of which enhances the integrity and efficiency, the possibility of multiple unstable economic environment functioning of management based on statistical and dynamical laws and laws that have a decisive character to the overall evolution of the company and society as a whole.

Thus, basing on synergistic approach provides mechanisms for self-organization and start self-building that involve the removal of all unnecessary, redundant in this system, streamlining processes and relationships between its elements and leaving only the strongest (or most efficient, optimal) in causing and carried out the relatively stable and simple structure of such records.

By application of a synergistic approach to the preparation of integrated reporting contributes to its overall dynamic and evolutionary development in today's uncertain economic environment, including in the presence of the economic crisis and overcoming it.

It is possible to achieve the synergy when providing integrated reporting with using a single conceptual framework to accounting information in all forms without exception reporting.

Under the concept of integrated reporting is meant the sum of beliefs, way of understanding the process of general interpretation of accounting information in such reports, the leading idea of systematic theoretical and methodological characteristics of the process which determines the strategy of action in implementing reforms for integrated statements in order to provide comprehensive information of internal and external users in managing their companies.

In the face of modern business, users require quality reporting accounting information on their activities. In this context it is appropriate in the preparation of integrated reporting to determine the appropriate parametric framework, based on the existing problems for which reporting is provided Such parametric principles should apply to all, without exception, accounts of all entities regardless of ownership.

Research Parametric training principles of integrated reporting should be based on a study of the following issues:

1. coordination parameter values: applications integrated reporting purpose integrated reporting system purposes for which the integrated reporting will be used;

2. user's requirements formation for integrated reporting;

3. determining the methods to be used for the preparation of integrated reporting.

When you create parametric training principles of integrated reporting view Midlton D. the existence of two provisions allow right up reports: general concepts and accounting methods [20, p. 37].

For the purpose of integrated reporting at its assembly is first necessary to define clearly the following parameters:

a purpose integrated reporting;

b scope;

c system, to achieve the objectives which provide a particular report.

Prerequisite for this is the formation compromises the values of the parameters. Overall, this compromise should be decisive in the development of theoretical and practical courses of training reports.

Table 1. The matrix of the key components of integrated reporting

\begin{tabular}{|c|c|c|}
\hline The future expenditure in management decisions & Balanced Scorecard in strategic management & $\begin{array}{l}\text { Information for social purposes in making social } \\
\text { decisions }\end{array}$ \\
\hline The accounting policies in transfer pricing & Modern tools of corporate culture management & Information risk management category \\
\hline Information for managing the value of company & Information for making environmental decisions & The quality of accounting information and accounting \\
\hline
\end{tabular}


Otherwise, there is a high probability of using the hermeneutic interpretation techniques for integrated reporting, which is a negative factor in management decisions. Hermeneutics is a common method in the field of legal interpretation, which involves the interpretation of texts. Using hermeneutics on integrated reporting significantly reduces its quality and usefulness due to the application of the information function. The ability to use the disputed hermeneutical methods in the interpretation of integrated reporting conditions taking inefficient management decisions that are based on false, given the current level of interpretation information. Therefore, presenting the integrated reporting should be clearly defined conceptual all parameters (scope, purpose, goals system), which was used in its preparation.

Based on the identified global challenges of the modern world total matrix components of integrated reporting economic actors may include 9 elements are presented in Table1.

The proposed matrix may be the basis for structuring such reports for companies since 9 considers the key information areas, taking into account the information needs of potential users, namely:

a need for assessing future costs in management decisions (predicted direction); information provision accounting transfer pricing (a response to challenges in global supply network, instability in the markets);

b need to manage cost economic entity (as the direction information entropy reduction and the impact of general economic instability);

c Balanced Scorecard (as information support Strategic management companies);

d information security corporate culture management (control effective instrument stability and development);

e information support of environmental decision-making (as direction control ambient pressure); information for social purposes (in response to challenge society to strengthen corporate social responsibility);

$\mathrm{f}$ information support risk management (as direction reduction unpredictability, particularly through forecasting);

$\mathrm{g}$ quality of accounting information and accounting (acts as a main thorough confidence in the statements as a whole).

In its turn, the quality derived from the reduction of information asymmetries, uncertainty in its recipient. As G. Akerlof noted [9], quality and uncertainty are interrelated. Thus, the purpose of management accounting is to reduce the information entropy (uncertainty or unpredictability information). Reducing uncertainty in user information determines the level of information saturation message.

Thus, the effectiveness of integrated reporting is determined to ensure it has reached the level of information capacity users. A preliminary study allowed distinguishing 7 basic criteria against which to evaluate the effectiveness of each report and statements as whole:

1. respond to environmental conditions for which, at the present stage of development, characterized by high degree of variability;

2. respond to inflationary pressures, the complexity of macroeconomic criteria and their importance in the formation of accounting information;

3. provide the ability to predict the effectiveness of decisions management;

4. respond to variation in ratings, criteria and methods of analysis in decision making;

5. used along with other national currency floating currencies;

6. consider the risks in decisions management;

7. provision the targeted adaptation to the needs of individual users reports.

Investigation of these issues have allowed to isolate a large number of requirements for integrated reporting required in scientific and practical literature, and state the complexity of their application in the absence of developments concerning the total systematization. Only in some special sources are summarized certain requirements for certain types of financial statements.

Thus, for financial accounting are formulated user's requirements at IFRS and GAAP. Under IFRS, in this context, the following qualitative characteristics of financial statements are considered: understandability, relevance, reliability (specified characteristics: a true representation, substance over form, neutrality, prudence, completeness), comparability [20].

More pragmatic and practical requirements are understood, formulated as a criterion GAAP should "be relevant to the case" to be reliable and comparable [21]. Therefore, timely information is able to influence decision-making.

To achieve the reliability of provided information in financial statements, the true impact of events on the economic situation of economic units should be impacted. This criterion is close to the requirement of "authenticity." However, the reliability assumes that if it is impossible to identify accurately some indicators of financial statements must use reasonable estimates. Therefore, taking into consideration a wide user needs, using the criterion of "reliability" is more reasonable.

The Council also requires that the financial statements provided in compliance with the principle of unity and was comparable to other reporting companies. With further interpretation of IFRS and GAAP above, requirements are considered as qualitative characteristics of information that causes ambiguity understanding.

In the context of integrated reporting and interpretation coordination, appropriate to use the following user requirements: understandability, relevance, reliability, neutrality, prudence, completeness, comparability, timeliness, efficiency.

Clarity provides an integrated representation of statements that are always clear. If you met this requirement must be based on the fact that users integrated reporting have appropriate knowledge of business management and 
accounting and are willing to learn the accounting information that is disclosed in reports with due diligence. In other words, integrated reporting should be clear to users, if they have sufficient knowledge and interest in the perception of accountability.

Integrated reporting companies should be appropriate. Relevance is the leading reporting requirements, as it determines the need for relevance in management reports. The criteria of relevance is the link integrated reporting purposes, facing the users reported providing relevant accounting information, software management capabilities regulation of the entity based on the reports received information.

Reliability of integrated reporting is determined by the absence in it of significant errors and bias. In order to ensure the reliability of integrated reporting in terms of its true representation advisable to detail this requirement through distribution into two components:

(a) reliability of the information integrated reporting;

(b) validity of integrated reporting.

When probability information integrated, reporting should understand user requirements for error-free formation statements in accordance with the methodology, the absence of errors and deviations from the established conceptual framework of the preparation of such statements, including at the international level, within the legal and regulatory fields States.

User requirements for the validity of integrated reporting should understand that statements should be composed based on accounting information, which is reflected in the primary documents.

Application requirements for neutrality integrated reporting provide no influence on decisions or judgments of users in order to achieve a predetermined result.

In the context of the need to meet the requirements of prudence in the preparation of integrated reporting it advisable to display information about the assets and income of the company, evaluated from the standpoint of prevention of overestimation and accounting data on liabilities and expenses entity when evaluating such methods are applied measures that prevent their understatement. In other words, integrated reporting should reflect the real potential of enterprises in the Evaluation aspect.

Another major requirement for integrated reporting is its completeness. At full understanding, the need for users to obtain all the information necessary to carry out the functions of management, legal and usefulness of the information provided in the report.

Comparability integrated reporting allows you to compare information on certain terms and identify trends by comparing changes in existing indicators provided systematic preparation of financial statements. Requirements for integrated reporting comparability due to the compile information need, such as individual segments, within the companies. Therefore, users must establish uniform reporting forms, rules for their preparation and provision both within the local and the state level. However, the ability to meet this requirement in view of the dynamism and fluidity of the economic environment requires a separate study.
In addition, integrated reporting should be timely, that is available when it is needed for users. Otherwise reporting would be inappropriate.

One of the important requirements is the cost (efficiency) integrated reporting that the benefit obtained from reports of accounting information for management exceed the costs of their training. Using a comprehensive limitation of "profit above costs" allows you to set the depth and level of detail required accounting information about the object against which it is provided in the financial statements.

In scientific literature, a significant number of other users reporting requirements that are either related or essentially mutually exclusive with respect to each other, which complicates their use in the preparation of financial statements, were described.

\section{Conclusions}

Generally, defined global challenges of the modern chaotic environment require the formation of innovative approaches to finance, accounting and management information support for management decisions.

The basis of the new financial theory should put a new theory of money as a measure of value; identify new equivalents of such value and mechanisms of their diversification. It also should be viewed not only general mechanisms of the financial system and build a new scientific paradigm financially.

Grounded theoretical and methodological development of integrated synergistic components reporting in response to requests for information economy and society allowed forming a matrix component of integrated reporting of economic agents, which includes 9 elements and determines the structure of such statements. Using the proposed seven basic criteria against which to evaluate the effectiveness of each report and integrated reporting in general allows for a high level of information saturation users taking into account not only existing but also potential needs.

The synergy of accounting, finance and management enables the formation of a new money theory, the development of integrated reporting as a response to social demands of society and the creation of fundamentally new paradigm of mental management companies.

\section{References}

[1] IMF, "Gradual upturn in Global Growth During 2013. IMF. FOR RELEASE: In Washington ", DC (EST): ten o'clock AM, January 23, 2013.

[2] J. Stiglitz, " What CAN save Euro? ", Project 12, 2011, P.5

[3] R. Engle, "Autoregressive Conditional Heteroskedastic with Estimates of the Variance of UK Inflation ", Econometrica, Vol. $50,1982$.

[4] R. Engle, "GARCH101: The Use of ARCH / GARCH Models in Applied Econometrics ", Journal of Economic Perspectives, vol. 15 , no. 4,2001 
[5] R. Engle, " Global Financial Stability and Long-term Risks ", $\mathrm{http} / / /$ slon.ru/economics/rossiya_dvigaetsya_ne_v_tom_napra vlenii_chto_i_dr-128832.xhtml

[6] A. Sheng , "Global Finance's Supply Chain Revolution ", Project Syndicate, VOL. 1, 2012, p. 3

[7] M. Friedman, "Lessons on Monetary Policy from the Journal of Economic", Journal of Economic, VOL. 3, 1988, pp. 51-72.

[8] J. Stiglitz, "The perils of 2012", Project Syndicate, 2012, P.5

[9] George Akerlof, "The Market for "Lemons": Quality Uncertainty and The Market Mechanism", The Quarterly Journal of Economics, vol .84, August 1970, pp. 488 - 500.

[10] S. Kuznetsova, " The Transformation of Accounting Systems in the Chaotic economy structuring: The synergetic Approach ", Risk and Decision Analysis, 2011, vol.2, no3, pp.151-160.

[11] S. Kuznetsova, A. Kuznetsov, " The Perspective of information Management Accounting in Ukraine: The synergistic Approach and Arrow's impossibility theorem", World Journal of Social Sciences, Zia World Press, Australia, vol. 4, no. 1, march 2014, pp. $140-153$.

[12] S. Kuznetsova, "Synergetic development accounting for the formation of "knowledge economy" in Ukraine", Melitopol, LLC "Publishing House MMD", 2010.
[13] F. L. Dermo H. P. Dzhenyk, M. Oreyly, "Audit Monomers", Moscow, Audit, Unity, 1997.

[14] E. Brukynh, "Intelligent capital", Petersburg, Peter, 2001.

[15] Bhimani, A. \& Bromwich M. 2009, "Management Accounting Retrospect and Prospect", CIMA, Elsevier.

[16] C. Armstrong, M. Barth, A. Jagolinzer, and E. Riedl "Market Reaction to the Adoption of IFRS in Europe", The Accounting Review, January 2010, vol. 85, no. 1, pp. 31-61.

[17] Mc Grow, “Accounting: System and Procedures", Hill Book Company.

[18] CJ McNair-Connolly, R Silvi, M Bartolin "Integrated Reporting and Value-Based Cost Management: A Natural Union", Integrated Reporting, 2013, Springer

[19] M. Friedman, "Money And Fiscal politics on Securing of Economic", Fundamentals of Moscow

[20] IFRS http://www.ifrs.org/Pages/default.aspx

[21] Generally Accepted Accounting Principles, GAAP USA http://www.fasb.org/home 